Article

\title{
Anti-Inflammatory Activity and Structure-Activity Relationships of Brominated Indoles from a Marine Mollusc
}

\author{
Tarek B. Ahmad ${ }^{1,2}$, David Rudd ${ }^{1}$, Joshua Smith ${ }^{1,3}$, Michael Kotiw ${ }^{2}$, Peter Mouatt ${ }^{3}$, \\ Lisa M. Seymour ${ }^{2}$, Lei Liu ${ }^{3}$ and Kirsten Benkendorff ${ }^{1, *}$ \\ 1 Marine Ecology Research Centre, School of Environment, Science and Engineering, Southern Cross \\ University, G.P.O. Box 157, Lismore, NSW 2480, Australia; t.ahmad.11@student.scu.edu.au (T.B.A.); \\ david.rudd@scu.edu.au (D.R.); Joshua.Smith@scu.edu.au (J.S.) \\ 2 Centre for Health Sciences Research, University of Southern Queensland, Toowoomba, QLD 4350, Australia; \\ Michael.Kotiw@usq.edu.au (M.K.); lisa.smr@gmail.com (L.M.S.) \\ 3 Analytical Research Laboratory, Southern Cross Plant Science, Southern Cross University, G.P.O. Box 157, \\ Lismore, NSW 2480, Australia; Peter.Mouatt@scu.edu.au (P.M.); ben.liu@scu.edu.au (L.L.) \\ * Correspondence: Kirsten.benkendorff@scu.edu.au; Tel.: +61-2-6620-3755; Fax: +61-2-6621-2669 \\ Academic Editor: Keith B. Glaser \\ Received: 14 March 2017; Accepted: 2 May 2017; Published: 6 May 2017
}

\begin{abstract}
Marine molluscs are rich in biologically active natural products that provide new potential sources of anti-inflammatory agents. Here we used bioassay guided fractionation of extracts from the muricid Dicathais orbita to identify brominated indoles with anti-inflammatory activity, based on the inhibition of nitric oxide (NO) and tumour necrosis factor $\alpha$ (TNF $\alpha)$ in lipopolysaccharide (LPS) stimulated RAW264.7 macrophages and prostaglandin E2 (PGE2) in calcium ionophore-stimulated 3 T3 ccl-92 fibroblasts. Muricid brominated indoles were then compared to a range of synthetic indoles to determine structure-activity relationships. Both hypobranchial gland and egg extracts inhibited the production of NO significantly with $\mathrm{IC}_{50}$ of 30.8 and $40 \mu \mathrm{g} / \mathrm{mL}$, respectively. The hypobranchial gland extract also inhibited the production of TNF $\alpha$ and PGE2 with $\mathrm{IC}_{50}$ of $43.03 \mu \mathrm{g} / \mathrm{mL}$ and $34.24 \mu \mathrm{g} / \mathrm{mL}$, respectively. The purified mono-brominated indole and isatin compounds showed significant inhibitory activity against NO, TNF $\alpha$, and PGE2, and were more active than dimer indoles and non-brominated isatin. The position of the bromine atom on the isatin benzene ring significantly affected the activity, with $5 \mathrm{Br}>6 \mathrm{Br}>7 \mathrm{Br}$. The mode of action for the active hypobranchial gland extract, 6-bromoindole, and 6-bromoisatin was further tested by the assessment of the translocation of nuclear factor kappa B (NFkB) in LPS-stimulated RAW264.7 mouse macrophage. The extract $(40 \mu \mathrm{g} / \mathrm{mL})$ significantly inhibited the translocation of NFKB in the LPS-stimulated RAW264.7 macrophages by $48.2 \%$, whereas $40 \mu \mathrm{g} / \mathrm{mL}$ of 6-bromoindole and 6-bromoistain caused a $60.7 \%$ and $63.7 \%$ reduction in $\mathrm{NFKB}$, respectively. These results identify simple brominated indoles as useful anti-inflammatory drug leads and support the development of extracts from the Australian muricid D. orbita, as a new potential natural remedy for the treatment of inflammation.
\end{abstract}

Keywords: marine natural products; inflammation; NO inhibition; Muricidae; isatin; Tyrian purple

\section{Introduction}

Inflammation is a complex mechanism involving the activation and deactivation of immune cells in response to stimuli and tightly regulated signalling pathways. If left unchecked, inflammation will result in cellular and tissue damage that can lead to chromic disease [1]. Macrophages play a key role in initiating and maintaining the inflammatory response, and are activated by pathogen associated molecules and cytokines, which stimulate pro-inflammatory signalling pathways [2]. Nuclear factor 
kappa $\mathrm{B}(\mathrm{NF} \kappa \mathrm{B})$ has long been considered a prototypical pro-inflammatory signalling molecule, activated by pro-inflammatory cytokines such as tumour necrosis factor $\alpha$ (TNF $\alpha)$ in the presence of viruses, genotoxic agents, or when stimulated by microbial constituents, including lipopolysaccharides (LPS) from bacterial cell walls [3]. Activation of the inhibitory subunit of NFKB, inhibitor of kappa B

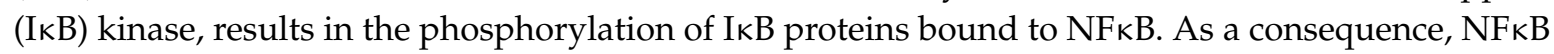
translocates to the nucleus, where it regulates the expression of a variety of transcription factors and co-factors, leading to the expression of pro-inflammatory enzymes like cyclooxygenase 2 (COX-2) and inducible nitric oxide synthase (iNOS), which are responsible for stimulating the production of inflammatory signalling molecules [3,4]. TNF $\alpha$ in particular, is considered one of the key inflammatory mediators in endotoxin-induced tissue injury and high levels of TNF $\alpha$ have been correlated with the severity of the inflammatory response [5]. Moreover, NO produced by iNOS is a prominent marker of inflamed tissue and can cause localised toxicity by producing reactive nitrogen oxide species (RNOS) [6] or by reacting directly with proteins or DNA [7]. Furthermore, prostaglandin E2 (PGE2) is produced as a result of the combined enzymatic activity of phospholipase A2 (PLA2) and COX-2, which is also regulated by the activation of NFKB. Therefore, the suppression of excessive production of NO, $\mathrm{TNF} \alpha$, and/or PGE2 in stimulated cells using in vitro assays provides an effective means to evaluate the anti-inflammatory activity of natural products and extracts [8] and intracellular translocation of NFkB can inform the mode of action [3,4].

For many centuries, natural products have provided a significant source of leads for drug development. Thirty-one marine compounds have now entered the clinical trials pipeline for drug development, of which seven have been approved by the Food and Drug Administration (FDA-approved) [9]. In particular, a significant number of anti-cancer drug leads have been isolated from marine molluscs [10]. However, only a small proportion of natural products isolated from marine molluscs have been investigated for anti-inflammatory potential [11]. Nevertheless, a lipid extract from the New Zealand Green lipped mussel Perna canaliculus has been clinically tested for the treatment of chronic inflammation and is commercially available as a nutraceutical [12]. Preliminary studies on the crude extracts from whelks in the Muricidae family of predatory gastropods indicate that these may also yield secondary metabolites with interesting anti-inflammatory properties. The acetone extracts of Drupella (Drupa) margariticola [13] and chloroform extracts from Purpura persica significantly reduced carrageenan-induced paw edema in rats, at concentrations well below the toxic limits [14]. Furthermore, lipid extracts from Rapana venosa were found to reduce inflammation and improve the healing of skin burns in Wistar rats [15]. These studies support further investigation of the bioactive compounds in muricid molluscs for potential development as anti-inflammatory treatments to replace the conventional steroidal and non-steroidal anti-inflammatory drugs, which have numerous side effects.

The Muricidae are well-known for their production of the dye molecule Tyrian purple (6,6 dibromoindigo, 1, Table 1) and related biologically active brominated indoles [16]. These compounds are generated from the precursor indole tyrindoxyl sulfate (2, Table 1), which is stored as a salt of the choline ester murexine in the hypobranchial glands and egg masses [17]. The intermediate dye precursors, tyrindoleninone (3, Table 1 ) and 6-bromoistain (4, Table 1), have specific anticancer activity, inducing apoptosis in a range of cancer cell lines in vitro [18-22] and DNA damaged cells to prevent colon cancer in vivo $[21,23,24]$. These bioactive monobrominated indoles dimerise to form the green coloured pigment tyriverdin (5, Table 1), the immediate precursor to Tyrian purple, which has no known anticancer activity but it is a potent bacteriostatic agent [25]. Minor pigments of Tyrian purple 6,6'-dibromoindirubin and 6-bromoindirubin (6, Table 1) have anti-proliferative properties and are potent inhibitors of glycogen synthase kinase-3 (GSK-3) [26]. Synthetic bromoindirubin derivatives with improved solubility and biological selectivity have been developed [27-29], leading to several patents over the last decade [30-32]. 
Table 1. Chemical structure properties and the source of compounds used in the study.

\begin{tabular}{|c|c|c|c|c|}
\hline & Chemical Structure & $\begin{array}{l}\text { Molecular } \\
\text { Weight }^{1}\end{array}$ & Log $p$ Value $^{2}$ & $\begin{array}{l}\text { Synthetic vs. } \\
\text { Purified }\end{array}$ \\
\hline 1 & & 420.06 & 4.47 & Synthetic \\
\hline 2 & & 337.18 & -0.346 & $\begin{array}{c}\text { Semi-purified } \\
\text { (methanol extract) }\end{array}$ \\
\hline 3 & & 256.12 & 2.89 & Purified \\
\hline 4 & & 226.03 & 1.61 & Synthetic \\
\hline 5 & & 514.25 & 4.66 & Purified \\
\hline 6 & & 356.18 & 4.08 & Synthetic \\
\hline 7 & & 262.27 & 2.9 & Synthetic \\
\hline 8 & & 147.13 & 0.83 & Synthetic \\
\hline 9 & & 226.03 & 1.61 & Synthetic \\
\hline 10 & & 226.03 & 1.59 & Synthetic \\
\hline 11 & & 196.05 & 2.94 & Synthetic \\
\hline 12 & & 304.22 & 3.00 & $\begin{array}{l}\text { Semi-purified } \\
\text { (chloroform } \\
\text { extract) }\end{array}$ \\
\hline 13 & & 258.13 & 3.38 & $\begin{array}{l}\text { Semi-purified } \\
\text { (chloroform } \\
\text { extract) }\end{array}$ \\
\hline
\end{tabular}

\footnotetext{
${ }^{1}$ The accurate mass based on the average of the $\mathrm{Br}^{79}$ and $\mathrm{Br}^{81}$ isotopes. ${ }^{2}$ The predicted $\log p$ values were calculated with molecular modelling using Molinspiration@ Cheminformatics (2016).
} 
Depending on the specific mode of action, anti-cancer compounds can often also exhibit anti-inflammatory activity $[3,33,34]$. In addition to anti-cancer properties, indirubin (7, Table 1$)$, a minor pigment in Tyrian purple dye mixtures, prevents the increase of reactive oxygen species (ROS), causing the attenuation of phagocytosis and induction of cell death in the presence of ATP [21,35]. Indirubin derivatives also inhibit the release of the pro-inflammatory cytokines interleukin (IL)- $1 \beta$ and IL-6 in mouse macrophage RAW264.7 cells stimulated with LPS [36]. The anti-cancer monobrominated indoles from Muricidae molluscs are yet to be tested for anti-inflammatory activity. However, the simple indole derivative isatin (8, Table 1) inhibits iNOS, COX-2, and TNF $\alpha$, which results in reduced PGE2 and NO levels in LPS-stimulated mouse macrophages [37]. These isatins, along with some indole derivatives, have been patented for the treatment of inflammation [38-40]. Consequently, further investigation of the anti-inflammatory properties of the brominated indoles from Muricidae are warranted. This study aims to investigate the inhibition of NO, TNF $\alpha, P G E 2$, and NFkB translocation by extracts and brominated indoles isolated from hypobranchial gland and egg masses of the Muricidae mollusc Dicathais orbita. In addition, the structure activity relationships of a number of brominated indoles were examined, using a suite of synthetic indole derivatives to determine if dimerization and the position of halogenation had any influence on activity.

\section{Results}

\subsection{Chemical Analysis of the Crude Extracts}

Liquid chromatography mass spectrometry (LC-MS) separations of the chloroform extracts confirmed the presence of brominated indoles typically found in D. orbita (Figure 1, Supplementary Figure S1) $[17,22,41]$. The fresh hypobranchial gland chloroform extract (Figure 1a) and the egg mass chloroform extract (Figure $1 \mathrm{~b}$ ) were dominated by 6-bromoistain (pseudomolecular ion $[\mathrm{M}+\mathrm{H}]^{+}$ $m / z$ 226, 228; $[\mathrm{M}+\mathrm{Na}]^{+} m / z 248,250, \mathrm{UV} \lambda_{\max } 212,256,308$, and $408 \mathrm{~nm}$ ) and tyrindoleninone (pseudomolecular ion $[\mathrm{M}+\mathrm{H}]^{+} m / z 256,258, \mathrm{UV} \lambda_{\max } 236,248,274,352,402 \mathrm{~nm}$ ) respectively, and contained smaller amounts of 6-bromoindole (pseudomolecular ion $[\mathrm{M}+2 \mathrm{H}]^{+} m / z 198,200$, UV $\lambda_{\max }$ $218,260,290 \mathrm{~nm}$ ) and tyriverdin (pseudomolecular ion $[\mathrm{M}+\mathrm{Na}]^{+} m / z 535,537,539$; $\mathrm{UV} \lambda_{\max } 236$, 252, 274, 352, 402, and $596 \mathrm{~nm}$ ) (Figure S1). Another brominated indole, tentatively identified as tyrindolinone $\left(\mathrm{C}_{10} \mathrm{H}_{10} \mathrm{BrNOS}_{2}\right)[17,20]$, detected in the hydrated form (pseudomolecular ion $[\mathrm{M}+\mathrm{H}]^{+}$ 306,308 , UV $\lambda_{\max } 224,254,338 \mathrm{~nm}$ ), was more abundant in the hypobranchial gland extracts (Figure 1a). The degraded hypobranchial gland extract did not appear to contain bromoisatin or tyrindoleninone (Figure 1c), and instead was dominated by unidentified compounds that did not produce paired isotopic ions indicative of brominated indoles. Due to the lack of anti-inflammatory activity, this degraded extract was not further characterized. The methanol extract from the hypobranchial gland (Figure 1d) was dominated by the precursor tyrindoxyl sulfate (pseudomolecular ion detected in negative ion mode $[\mathrm{M}]^{-} m / z 336,338, \mathrm{UV} \lambda_{\max } 225$ and $\left.300 \mathrm{~nm}\right)$ and contained some murexine $\left([\mathrm{M}]^{+}\right.$ $m / z 224$, UV $\lambda_{\max } 266 \mathrm{~nm}$ (Figure S1)).

Gas chromatography mass spectrometry (GC-MS) analysis of the hypobranchial gland chloroform extract further confirmed the dominant volatile compounds in the extract were brominated indoles (Figure 2, Supplementary Figure S2). Based on comparison to mass spectral databases ( $\geq 98 \%$ match), these compounds were identified as methyl 6-bromoisatin, 6-bromo-2,3 dihydro indole-2,3-diol, 6-bromoindoxyl, tyrindoleninone, tyrindoxyl, and 6-bromoisatin (Figure 2a). Tyrindoxyl is a transient compound that readily oxidizes to tyrindoleninone [42,43]. GC-MS confirmed the purity of tyrindoleninone in the isolated orange fraction eluted by silica column chromatography with $20 \%$ dichloromethane (DCM) in hexane. 


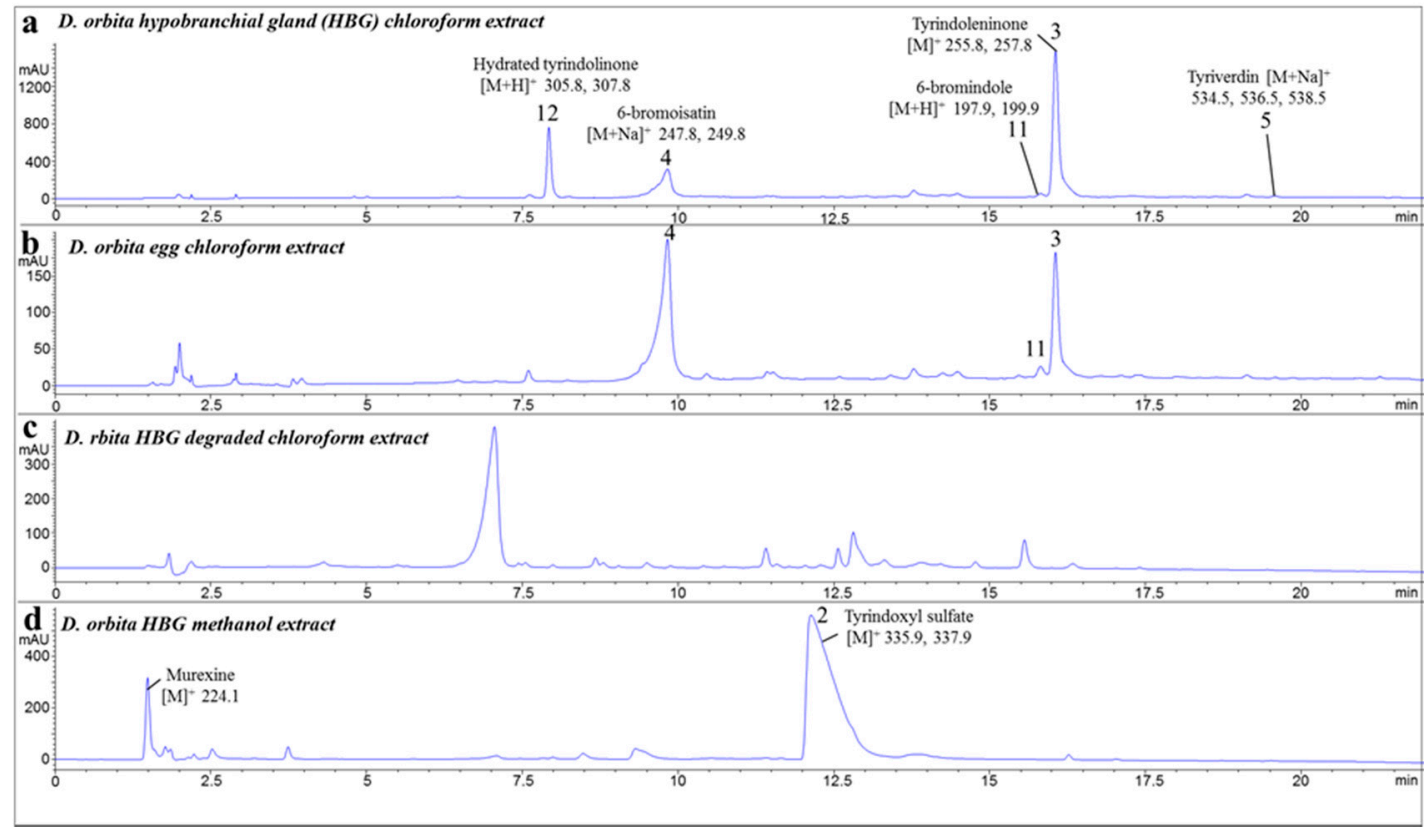

Figure 1. Liquid chromatography mass spectrometry (LC-MS) chromatographs of several extracts from Dicathais orbita showing brominated indoles identified by mass spectrometry (molecular ions for $\mathrm{Br}^{79}, \mathrm{Br}^{81}$ ): (a) chloroform extract of the hypobranchial gland; (b) chloroform extract of the egg mass; (c) degraded chloroform extract of the hypobranchial gland; and (d) methanol extract of the hypobranchial gland. Mass spectra for the main brominated indoles are shown in Supplementary Figure S1.

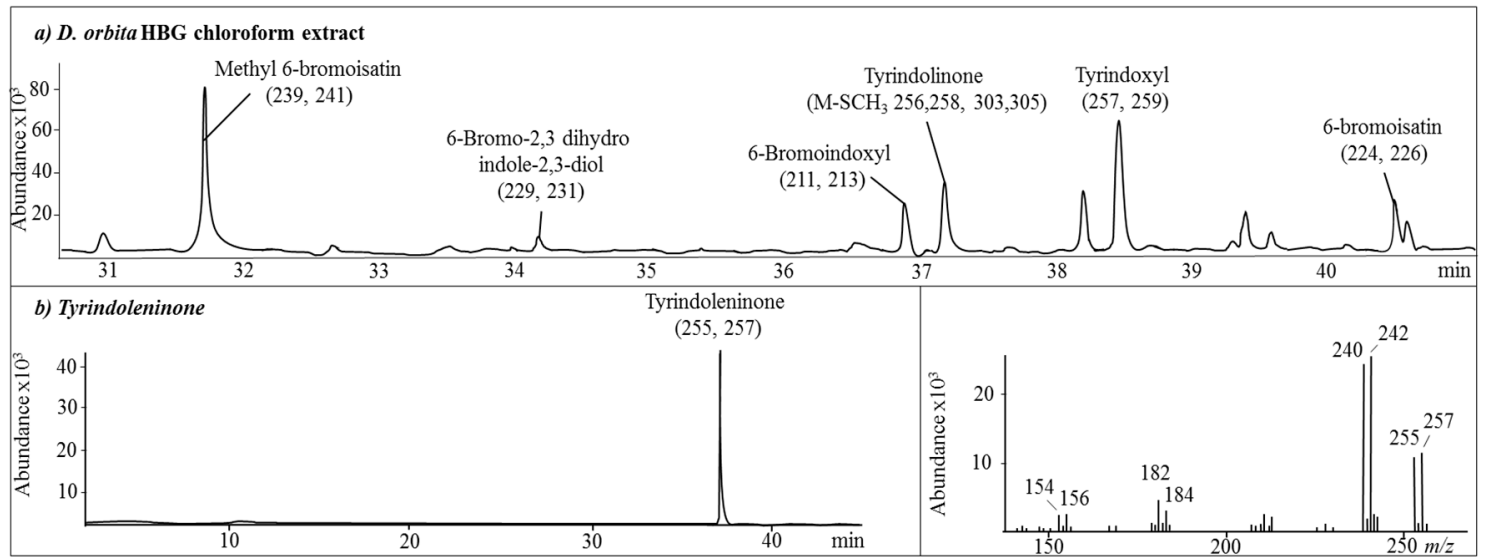

Figure 2. Gas chromatography mass spectrometry (GC-MS) of the chloroform extracts from Dicathais orbita showing brominated indoles identified by mass spectrometry (molecular ions for $\mathrm{Br}^{79}, \mathrm{Br}^{81}$ ). GC-MS chromatograms of the (a) hypobranchial gland chloroform extract; (b) purified fraction containing tyrindoleninone, with the associated mass spectral fragmentation pattern. The brominated compounds were identified based on characteristic mass isotopic patterns for brominated indoles $\left(\mathrm{Br}^{79}\right.$ and $\left.\mathrm{Br}^{81}\right)$, and matched to the NIST02 database. The structures for the main compounds tested are provided in Table 2. The mass spectra for the brominated indoles in the extract are shown in Supplementary Figure S2. 
Table 2. Anti-Inflammatory Inhibitory Concentration $50\left(\mathrm{IC}_{50}\right)$ for the brominated indole natural products from Dicathais orbita and synthetic analogues. NA = not active at maximum test concentration $50 \mu \mathrm{g} / \mathrm{mL}$; NT = Not tested.

\begin{tabular}{|c|c|c|c|c|c|c|c|c|c|c|c|c|}
\hline Compound & $\mathbf{R}^{1}$ & $\mathbf{R}^{2}$ & $\mathbf{R}^{3}$ & $\mathrm{R}^{4}$ & $\mathbf{R}^{5}$ & $R^{6}$ & $\mathbf{R}^{7}$ & $\begin{array}{l}\text { Cytotoxicity * } \\
\text { RAW264.7 }\end{array}$ & $\begin{array}{c}\text { Cytotoxicity * } \\
\text { 3T3 ccl-92 }\end{array}$ & $\begin{array}{c}\text { NO } \\
\mathrm{IC}_{50} \mu \mathrm{M}\end{array}$ & $\begin{array}{c}\text { TNF } \alpha \\
\text { IC }_{50} \mu \mathrm{M}\end{array}$ & $\begin{array}{c}\text { PGE2 } \\
\text { IC }_{50} \mu \mathrm{M}\end{array}$ \\
\hline 6,6 dibromoindigo (1) & $\mathrm{H}$ & $\mathrm{Br}$ & $\mathrm{H}$ & $\mathrm{O}$ & $\mathrm{Y}$ & $x$ & $\mathrm{Br}$ & NA & NA & NA & NT & NT \\
\hline Tyrindoxyl sulfate (2) & $\mathrm{H}$ & $\mathrm{Br}$ & $\mathrm{H}$ & $\mathrm{OSO}_{3}^{-}$ & $\mathrm{SCH}_{3}$ & - & - & NA & NA & NA & NT & NT \\
\hline Tyrindoleninone (3) & $\mathrm{H}$ & $\mathrm{Br}$ & $\mathrm{H}$ & $\mathrm{O}$ & $\mathrm{SCH}_{3}$ & - & - & $>195.22$ & NA & 103 & 157 & NT \\
\hline 6-bromoisatin (4) & $\mathrm{H}$ & $\mathrm{Br}$ & $\mathrm{H}$ & $\mathrm{O}$ & $\mathrm{O}$ & - & - & NA & NA & 120 & 123 & $>221.21$ \\
\hline Tyriverdin (5) & $\mathrm{H}$ & $\mathrm{Br}$ & $\mathrm{H}$ & $\mathrm{O}$ & $\mathrm{SCH}_{3}, \mathrm{Y}$ & $\mathrm{SCH}_{3}, \mathrm{X}$ & $\mathrm{Br}$ & NA & NA & $>97.23$ & NT & NT \\
\hline 6-bromoindirubin (6) & $\mathrm{H}$ & $\mathrm{Br}$ & $\mathrm{H}$ & $\mathrm{Y}$ & $\mathrm{O}$ & X & $\mathrm{H}$ & $\sim 140.38$ & NT & NA & NT & NT \\
\hline Indirubin (7) & $\mathrm{H}$ & $\mathrm{H}$ & $\mathrm{H}$ & $\mathrm{Y}$ & $\mathrm{O}$ & $X$ & $\mathrm{H}$ & NA & NA & NA & NT & NT \\
\hline Isatin (8) & $\mathrm{H}$ & $\mathrm{H}$ & $\mathrm{H}$ & $\mathrm{O}$ & $\mathrm{O}$ & - & - & NA & NA & 339.83 & $>339.83$ & NT \\
\hline 5-bromoisatin (9) & $\mathrm{H}$ & $\mathrm{H}$ & $\mathrm{Br}$ & $\mathrm{O}$ & $\mathrm{O}$ & - & - & $\sim 221.21$ & NA & 152 & 38 & NT \\
\hline 7-bromoisatin (10) & $\mathrm{Br}$ & $\mathrm{H}$ & $\mathrm{H}$ & $\mathrm{O}$ & $\mathrm{O}$ & - & - & $>221.21$ & $>221.21$ & NA & NT & NT \\
\hline 6-bromoindole (11) & $\mathrm{H}$ & $\mathrm{Br}$ & $\mathrm{H}$ & $\mathrm{H}$ & $\mathrm{H}$ & & & $>255.04$ & NA & 187 & 150 & 223 \\
\hline
\end{tabular}

* The test concentration $(\mu \mathrm{M})$ which causes toxicity (reduction in cell viability) toward the cell line after $24 \mathrm{~h}$ of incubation; $>$ indicates some activity at the maximum test concentration but with $<50 \%$ reduction in cell viability or inhibition of the inflammatory markers. indicates close to $50 \%$ reduction in viability at the maximum test concentration. 
Tyriverdin is not volatile and is highly insoluble in all solvents. It precipitated out of solution during LC-MS, hence this semi-purified compound could only be tentatively identified using thin layer chromatography (TLC; r.f value $=0.32$ ) and the change from a green to purple colour following exposure to light confirmed that is was mostly likely to be tyriverdin [25].

\subsection{Cytotoxicity Assays}

There was no cytotoxicity observed for any of the D. orbita extracts used in this study, at concentrations up to $50 \mu \mathrm{g} / \mathrm{mL}$, against both RAW264.7 and 3T3 cell lines (Table 2) (cell viability was $100 \%$ in all triplicate wells after $24 \mathrm{~h}$ of incubation). Therefore, this concentration was chosen as the highest concentration for anti-inflammatory testing. However, at $50 \mu \mathrm{g} / \mathrm{mL}, 6$-bromoindirubin, tyrindoleninone, 5-bromoisatin, 7-bromoisatin, and 6-bromoindole showed minor toxicity toward RAW264.7 cells after $24 \mathrm{~h}$ of incubation with an average $\%$ viability of $56.2 \%, 84.1 \%, 55.0 \%, 81.9 \%$, and $66.4 \%$, respectively (Table 2). Only 7-bromoisatin showed slight toxicity at $50 \mu \mathrm{g} / \mathrm{mL}$ against the $3 \mathrm{~T} 3$ fibroblast cell line after $24 \mathrm{~h}$ of incubation, with $80.9 \%$ viability when compared to the DMSO-treated wells.

\subsection{NO Inhibition Assay}

The chloroform extracts from D. orbita (hypobranchial gland and egg extract) used in this study showed significant inhibition of NO production by LPS-stimulated RAW264.7 cells at concentrations down to $10 \mu \mathrm{g} / \mathrm{mL}$, in comparison to the DMSO control $(p<0.001)$ (Figure $3 \mathrm{~A})$. At the maximum test concentration of $50 \mu \mathrm{g} / \mathrm{mL}$, the hypobranchial and the egg extract reduced NO production on average by $80 \%$ and $57 \%$ respectively, compared to the well-known anti-inflammatory drug dexamethasone, which caused $56 \%$ inhibition at the working concentration of $2.5 \mu \mathrm{M}$ (Figure 3A). The methanol extract and the degraded hypobranchial gland chloroform extract, however, showed no inhibition of NO production in the LPS-stimulated RAW264.7 mouse macrophages. The methanol extract was dominated by tyrindoxyl sulfate (Figure $1 b$ ), so the lack of NO inhibitory activity in this extracts indicates that this brominated indoxyl-sufate salt also does not have any associated activity (Table 2).

The purified brominated indoles tyrindoleninone and tyriverdin significantly inhibited the production of $\mathrm{NO}$, down to $0.08 \mu \mathrm{g} / \mathrm{mL}$ and $10 \mu \mathrm{g} / \mathrm{mL}$, respectively $(p<0.05$, Figure $3 \mathrm{~B})$. The $\mathrm{IC}_{50}$ for tyrindoleninone was $26.4 \mu \mathrm{g} / \mathrm{mL}(103 \mu \mathrm{M})$, whereas tyriverdin caused less than $50 \%$ reduction in NO at the maximum test concentration (Table 2). The synthetic version of the natural product 6-bromoisatin significantly inhibited NO production down to $0.4 \mu \mathrm{g} / \mathrm{mL}$ (Figure 3B), with an $\mathrm{IC}_{50}$ of $27.1 \mu \mathrm{g} / \mathrm{mL}$ $(120 \mu \mathrm{M})$ (Table 2). The non-brominated compound isatin showed weak NO inhibitory activity causing on average $34 \%$ reduction at $50 \mu \mathrm{g} / \mathrm{mL}$ (Figure $3 \mathrm{C}$ ), with a predicted $\mathrm{IC}_{50}$ of $63.3 \mu \mathrm{g} / \mathrm{mL}(430 \mu \mathrm{M})$. The synthetic 5-bromoisatin had higher activity (Figure 3C) with a predicted $\mathrm{IC}_{50}$ of $34.3 \mu \mathrm{g} / \mathrm{mL}(151.6 \mu \mathrm{M}$, Table 1), whilst 7-bromoisatin showed lower activity, with less than $5 \%$ inhibition at $50 \mu \mathrm{g} / \mathrm{mL}$ (Figure 3C). The 6-bromoindole showed similar activity to 5- and 6-bromoisatin (Figure 3C, Table 2). However, all the synthetic dimers including indirubin, 6,6 dibromoindigo, and 6-bromoindirubin showed minimal inhibitory activity (Figure 3D). 
A)

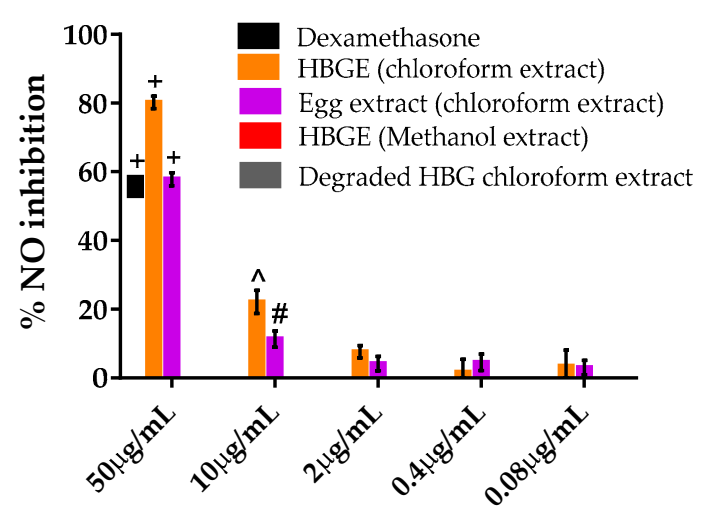

C)

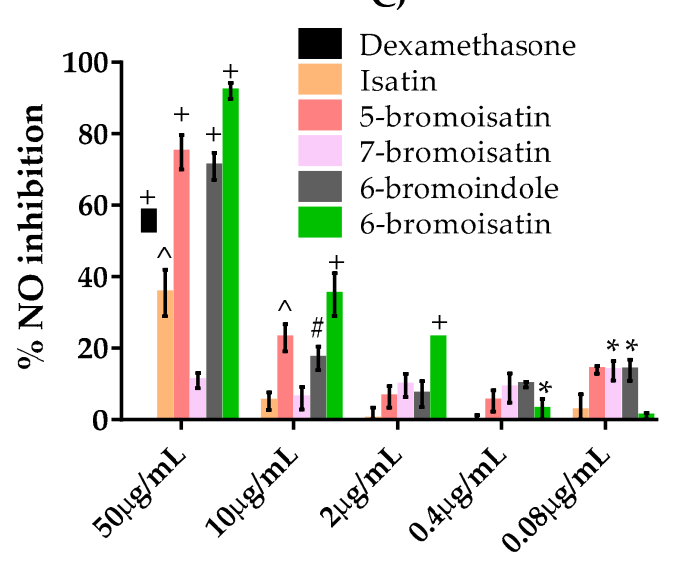

B)

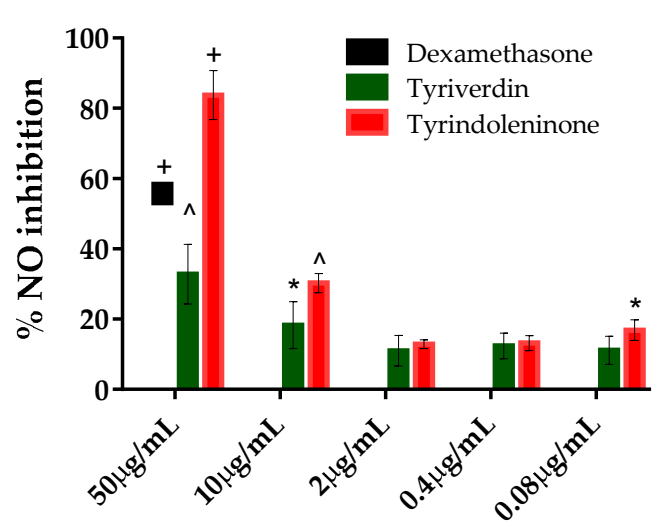

D)

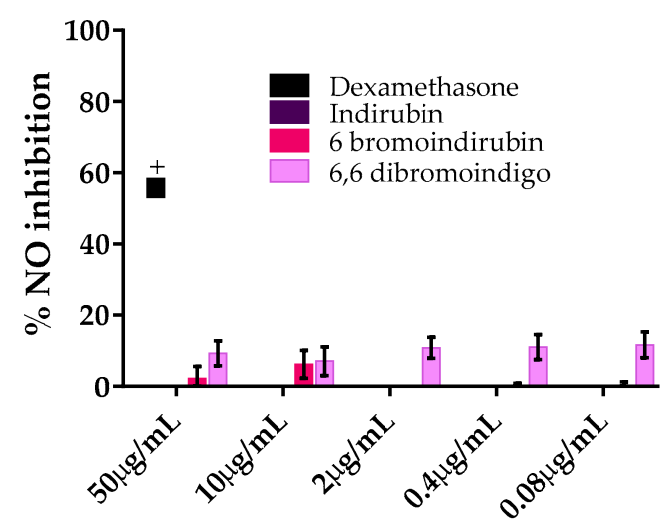

Figure 3. NO inhibition in RAW264.7 mouse macrophages stimulated with lipopolysaccharide (LPS) and treated with extracts from Dicathais orbita, purified brominated indoles, and synthetic analogues. Data are expressed as \% inhibition of NO production relative to the negative control DMSO: (A) extracts from the hypobranchial glands (HBG) and egg capsules; (B) the purified natural products tyrindoleninone and tyriverdin; (C) the monomer synthetic indoles isatin, 5-bromoisatin, 7-bromoisatin, and 6-bromoindole; (D) the dimer synthetic indoles indirubin, 6-bromoindirubin, and 6,6 dibromoindigo. Data shown are means \pm SEM from three separate experiments performed in triplicate. The symbols above the bars indicate statistically significant differences in the amount of nitrite in the treatments compared to the DMSO control. ${ }^{*} p<0.05$, \# $p<0.01,{ }^{\wedge} p<0.001,+p<0.0001$ versus untreated, stimulated cells (LPS + DMSO).

\subsection{TNF $\alpha$ Inhibition}

The levels of TNF $\alpha$ in the supernatant were measured in LPS-stimulated RAW264.7 cells pre-treated for one hour with the chloroform extract from the hypobranchial gland (HBG), isatin, 5-bromoisatin, 6-bromoisatin, 6-bromoindole, and tyrindoleninone (Figure 4). The HBG extract showed significant inhibition of TNF $\alpha$, down to $0.4 \mu \mathrm{g} / \mathrm{mL}(p<0.01)$. At $50 \mu \mathrm{g} / \mathrm{mL}$ this extract caused $>60 \%$ inhibition of $\mathrm{TNF} \alpha$, which was greater than the positive control dexamethasone (Figure 4A). All the brominated indoles tested also showed significant inhibition and for 5-bromoisatin at $50 \mu \mathrm{g} / \mathrm{mL}$, inhibition reached $100 \%$, with an $\mathrm{IC}_{50}$ of $38.05 \mu \mathrm{M}$ (Table 2). The $\mathrm{IC}_{50}$ of the non-brominated indole, isatin, was predicted to be $717.27 \mu \mathrm{M}$ (above the maximum test concentration), and much less active than the brominated indoles 6-bromoisatin $(122.65 \mu \mathrm{M}), 6$-bromoindole $(150.01 \mu \mathrm{M})$, and tyrindoleninone $(157.12 \mu \mathrm{M})$ (Table 2$)$. 
(A

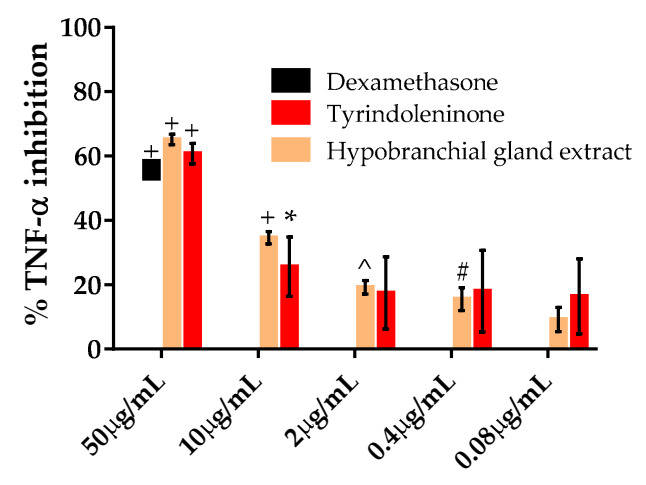

(B

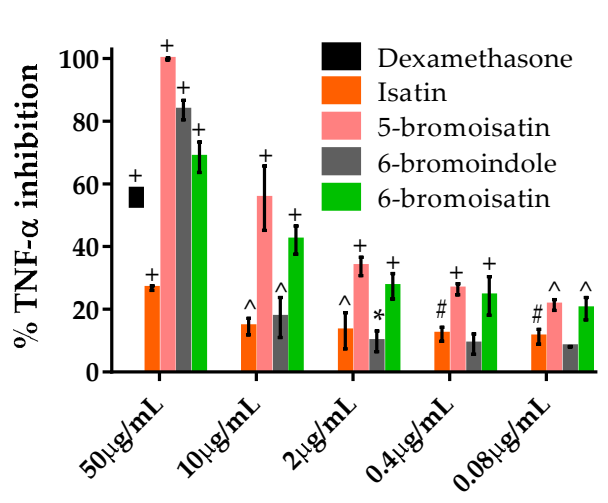

Figure 4. Percent inhibition of TNF $\alpha$ in LPS stimulated RAW264.7 macrophages after treatment with Dicathais orbita hypobranchial gland (HBG) extract and associated brominated indoles: (A) chloroform extract and tyrindoleninone, purified from the HBG extract; (B) synthetic isatin and indole compounds. Data shown are means \pm SEM from three separate experiments performed in triplicate. The symbols above the bars indicate statistical significance of the differences in the amount of TNF $\alpha$ in the samples compared to the DMSO control. ${ }^{*} p<0.05, \# p<0.01,{ }^{\wedge} p<0.001,+p<0.0001$ versus LPS + DMSO.

\subsection{PGE2 Inhibition Assay}

The effect of different concentrations of the HBG chloroform extract and the naturally occurring compounds, 6-bromoisatin and 6-bromoindole, on the generation of PGE2 in 3T3 ccl-92 fibroblast was examined. The highest inhibition rate was found using the HBG extract, which inhibited the production of PGE2 by more than $65 \%$ at $50 \mu \mathrm{g} / \mathrm{mL}(p<0.0001)$, which is greater than the inhibition caused by indomethacin at the $100 \mu \mathrm{M}$ concentration (Figure 5). In addition, 6-bromoindole caused a significant dose response for PGE2 inhibition, with significant inhibition compared to the solvent control even at the lowest concentration $(0.08 \mu \mathrm{g} / \mathrm{mL})(p<0.05)$ and $\mathrm{IC}_{50}$ of $223.28 \mu \mathrm{M}$ (Table 2). Similarly, 6-bromoisatin caused a significant dose response with $40 \%$ inhibition at $50 \mu \mathrm{g} / \mathrm{mL}$ and just $10 \%$ inhibition at $0.08 \mu \mathrm{g} / \mathrm{mL}(p<0.0001)$, with an $\mathrm{IC}_{50}$ of $293.02 \mu \mathrm{M}$ (Table 2$)$.

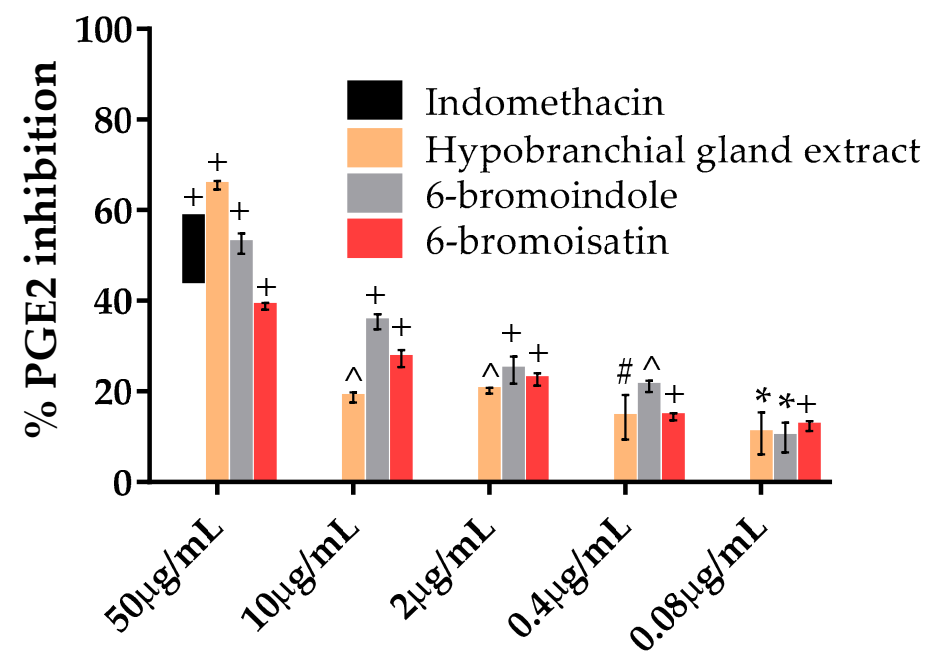

Figure 5. PGE2 inhibition in calcium ionophore stimulated $3 \mathrm{~T} 3 \mathrm{ccl}-92$ fibroblasts after exposure to a chloroform extract from the hypobranchial glands of Dicathais orbita and the associated brominated compounds 6-bromoisatin and 6-bromoindole. Data shown are means \pm SEM from three separate experiments performed in triplicate. Symbols above the bars indicate statistically significant differences in the amount of PGE2 produced in the samples compared to the DMSO treatment. ${ }^{*} p<0.05, \# p<0.01$, ^ $p<0.001,+p<0.0001$ versus LPS + DMSO. 


\subsection{Assessment of NFKB Translocation}

To investigate the mode of action of the active extract and brominated indoles, the ability to inhibit the translocation of the NFKB in LPS-stimulated RAW264.7 was assessed. LPS caused a marked increase in the translocation of $\mathrm{NF}_{\kappa} \mathrm{B}$ into the nucleus, as indicated by significant increases in the red fluorescence intensity inside the nucleus (Figure 6A,B). The HBG chloroform extract, 6-bromoisatin, isatin, and 6-bromoindole at $40 \mu \mathrm{g} / \mathrm{mL}$ concentration were all found to cause a noticeable inhibition of the translocation of NFKB in the LPS-induced RAW264.7 cells, compared to DMSO (Figure 6A). 6-Bromoindole inhibited the translocation of $\mathrm{NF} \kappa \mathrm{B}$ by $63.2 \%$ on average, whereas 6-bromoisatin, HBG extract, and isatin caused 60.7, 48.2, and 45.7\% inhibition, respectively (Figure 6C).

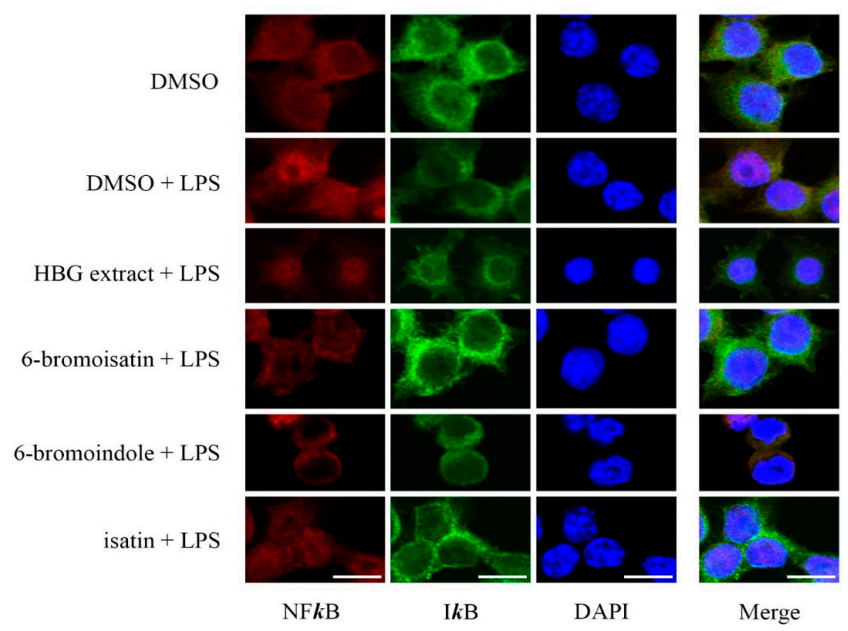

(A)
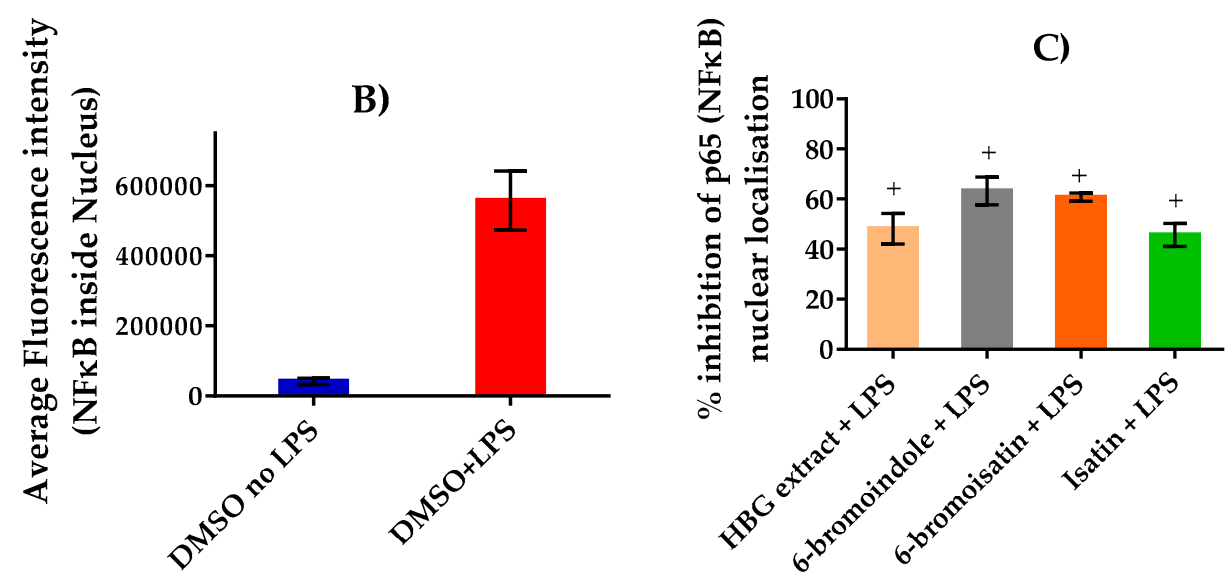

Figure 6. The inhibition of nuclear factor kappa B (NFkB) translocation: (A) representative images of the RAW264.7 cells obtained by an Olympus FV i10 confocal microscope showing the effect of each treatment on the translocation of the p65 subunit of the NFKB stained with Alexa fluor 594 (red fluorescence) into the nucleus. The inhibitor subunit was stained with Alexa fluor 488 (green fluorescence) to highlight the inactivated NFKB in the cytoplasm. 4',6-Diamidino-2-phenylindole (DAPI; blue) was used to stain the nucleus. Scale bar set to $10 \mu \mathrm{m}$; (B) LPS-induced activation of NFKB in RAW264.7 showing the average intensity of the NFKB fluorescence (red) inside the nucleus; (C) mean $\%$ NFKB inhibitory activity of the hypobranchial gland (HBG) extract from Dicathais orbita and the synthetic compounds 6-bromoisatin, isatin, and 6-bromoindole, based on the reduction of fluorescence intensity relative to the DMSO + LPS stimulated control. All test compounds/extracts were tested at a final concentration of $40 \mu \mathrm{g} / \mathrm{mL}$. Data shown are mean \pm SEM from three separate experiments. " $+"=p<0.0001$ versus LPS + DMSO. All data were obtained using the image processing and analysis software ImageJ (https:/ /imagej.nih.gov/ij/). 


\section{Discussion}

The development of new natural products or drugs that prevent the over-production of NO and pro-inflammatory cytokines, like TNF $\alpha$ and PGE2, has become an important focus of research for the treatment of chronic inflammatory diseases. In this study, crude organic extracts from the Australian marine mollusc D. orbita were tested and found to have NO, TNF $\alpha$, and PGE2 inhibitory activity, but no cytotoxicity at the active concentrations. Consistent with previous studies, the active lipophilic (chloroform) extracts from the hypobranchial glands and egg masses were found to contain the brominated indole intermediate precursors to Tyrian purple dye [17]. Purification of the chloroform extract led to the isolation of tyrindoleninone and tyriverdin, both of which were found to significantly inhibit NO production, along with 6-bromoisatin and several other synthetic monobrominated indoles. By comparison, the synthetic indole dimer pigments and the polar methanol extract containing the salt precursors, tyrindoxyl sulphate, and murexine, were not found to inhibit the production of NO in LPS stimulated RAW cells. This indicates that lipophilic extracts from D. orbita containing small brominated indoles have potential use as anti-inflammatory agents, in addition to their previously reported anti-cancer properties [21-24].

A range of synthetic brominated indole derivatives were tested to establish the structure-activity relationships for $\mathrm{NO}$ inhibition. Isatin showed mild anti-inflammatory activity, significantly inhibiting the production of $\mathrm{NO}$ with $\mathrm{IC}_{50}$ at $\sim 339.8 \mu \mathrm{M}$ and TNF $\alpha$ at concentrations down to $0.5 \mu \mathrm{M}$ (but with $\mathrm{IC}_{50}$ over the maximum test concentration of $50 \mu \mathrm{g} / \mathrm{mL}$ ). This activity is generally consistent with that reported by Matheus et al. [37], who found that isatin significantly inhibited LPS and interferon- $\gamma$ induced NO production in RAW264.7 cells, at even lower concentrations of 10-100 $\mu \mathrm{M}$, whereas $\mathrm{TNF} \alpha$ was inhibited at $100 \mu \mathrm{M}$, although they did not establish the minimum effective dose. These researchers also tested a range of simple halogenated isatin derivatives and found that whilst most were active in the test range, the specific activity varied according to the halogen substituent and position. Likewise, our results indicate that the presence and position of bromine on the aromatic ring can affect the activity, with 6-bromoisatin $>5$-bromoisatin $>$ isatin $>7$-bromoisatin for NO inhibition, whereas for TNF $\alpha$ inhibition, 5-bromoisatin $>6$-bromoisatin $>$ isatin. Matheus et al. [37] reported that 4-bromoisatin and 5-iodoisatin did not inhibit NO production or PGE2, whereas three chlorinated isatin derivatives and 5-flouroisatin inhibited NO and PGE2 at similar concentrations to isatin. In the $\mathrm{TNF} \alpha$ production assay, however, 5 -iodoisatin $=6$-chloroisatin $>$ isatin $>5$-chloroisatin $=7$-chloroisatin $>4$-bromoisatin $=4$-flouroisatin [37]. These results indicate that the anti-inflammatory activity of isatins depends on both the position and type of halogen substituent, with different patterns for TNF $\alpha$ compared to NO and PGE2 inhibition, suggesting that there may be more than one potential target site or mode of action [37]. Nevertheless, the results from both studies overall suggest that substitution of bromine into the $C_{5}$ and $C_{6}$ position on isatin based compounds effectively increases the anti-inflammatory activity. Previous studies on the anti-cancer activity of isatin derivatives also suggest that bromine substitution on $C_{5}$ or $C_{6}$ can result in increased biological activity $[18,44,45]$.

In addition to the brominated isatin derivatives, we found similar anti-inflammatory activity with synthetic 6-bromoindole and naturally derived 6-brominated indole derivatives. This suggests that the specific functional group in position 2 on the indole ring may not be important for the inhibition of NO, PGE2, or TNF $\alpha$. Nevertheless, dimerisation of the indoles was found to substantially reduce the activity. The lack of inhibitory activity associated with the brominated indirubin and indigo dimers could be due to their insolubility, as indicated by their calculated $\log p$ values of $>4$ (Table 2). Kim and Park [36] synthesised a soluble 3 monoxime derivative of indirubin and demonstrated significant anti-inflammatory activity, including the inhibition of NO and PGE2. However, in our study, the relatively soluble nonbrominated indirubin was also not active and showed a tendency towards stimulating the production of NO in LPS stimulated RAW cells. This result was unexpected given that indirubin is known to inhibit glycogen synthase kinase-3 (GSK3) [45], which promotes anti-inflammatory responses, including LPS induced NO production [46]. Furthermore, indirubin has been identified as an active ingredient in the traditional medicinal plants Isatis tinctoria and 
Polyglonum tinctorium used to treat inflammation and has demonstrated in vivo anti-inflammatory properties [47-49]. Nevertheless, consistent with our results, indigo and alkaloid fractions obtained from the plant Indigofera suffruticosa have been shown to stimulate NO production [50]. This suggests indigo and indirubin may have immunomodulatory activity that depends on the specific cell type and type of stimulation.

Recent studies have showed that many anti-inflammatory drugs, including dexamethasone, can supress the production of the pro-inflammatory factors by inhibiting the translocation of NFKB [51,52]. Here we provide preliminary evidence that the hypobranchial gland extracts of $D$. orbita, along with isatin, 6-bromoisatin, and 6-bromoindole, exerted anti-inflammatory effects by inhibiting the translocation of $\mathrm{NF} \kappa \mathrm{B}$, thus resulting in the inhibition of $\mathrm{NO}, \mathrm{TNF} \alpha$, and PGE2 production. Consistent with this, the indirubin analogue indriubin-3-monoxime was found to downregulate NFKB activation, correlating with a reduction of inducible NO synthase (iNOS) and cycloxygenase-2 [36]. Inhibiting the translocation of $\mathrm{NF} \kappa \mathrm{B}$ prevents the undesirable over production of pro-inflammatory cytokines and NO from the iNOS pathway. Matheus et al. [37] found that isatin and its halogenated derivatives significantly inhibit iNOS and COX-2 protein expression, thus resulting in a significant reduction of $\mathrm{NO}$ and PGE2 production. The inhibition of the NFKB translocation signalling pathway is consistent with the duel anti-inflammatory activities and anti-cancer activities of halogenated indole, isatin, and indirubin derivatives from Muricidae molluscs [18,20,21,26,53].

In conclusion, this study supports the nutraceutical potential of extracts from the hypobranchial glands of the Australian muricid D. orbita for anti-inflammatory applications. It also confirms that simple brominated isatins have anti-inflammatory activity including the inhibition of NO, PGE2, and $\mathrm{TNF} \alpha$, which are likely to be mediated by the inhibition of NFKB translocation, thus contributing to their potential application and development as anti-inflammatory and anti-cancer agents.

\section{Materials and Methods}

\subsection{Chemicals and Reagents}

Escherichia coli LPS (O128:B12, Sigma), sulfanilic acid, N-(1-Naphthyl) ethylenediamine (NED), $85 \%$ orthophosphoric acid sodium nitrite $\left(\mathrm{NaNO}_{2}\right)$, isatin $(8$, Table 1), 5-bromoisatin $(9$, Table 1$)$, 6-bromoisatin (4, Table 1), 7-bromoisatin (10, Table 1), 6-bromoindole (11, Table 1) were purchased from Sigma-Aldrich (St. Louis, MO, USA). Tyrian purple (6,6 dibromoindigo (1, Table 1), indirubin (7, Table 1), and 6-bromoindirubin (6, Table 1) were obtained from A. L. Skaltsounis (University of Athens). Penicillin-streptomycin solution, Dulbecco's Modified Eagle's Medium (DMEM), fetal bovine serum (FBS), sodium pyruvate, and L-glutamine were from Life Technology Australia (Mulgrave, VIC, Australia). RAW264.7 mouse macrophages and 3T3 Swiss albino (ATCC ${ }^{\circledR}$ CCL92 ${ }^{\mathrm{TM}}$ ) cell lines were obtained from the American Type Culture Collection (ATCC ${ }^{\circledR}$, Manassas, VA, USA).

\subsection{Cell Culture}

The Murine RAW264.7 and 3T3 fibroblast cell culture were maintained in 10\% FBS supplemented with DMEM, $100 \mu \mathrm{g} / \mathrm{L}$ streptomycin, and $100 \mathrm{IU} / \mathrm{mL}$ penicillin at $37^{\circ} \mathrm{C}$ and $5 \% \mathrm{CO}_{2}$ atmosphere. Cells were passaged every $48-72 \mathrm{~h}$ in a split ratio of 1:10-1:20. Passages used in this study were between passage 7 and passage 25 .

\subsection{Mollusc Collection, Dissection, and Extraction}

Medium sized Dicathais orbita (40-90 mm shell length) were collected from inter-tidal reefs along the north coast of NSW, Australia, under the Southern Cross University NSW Fisheries exemption permit F89/1171-6.0. The collected snails were kept frozen until needed. In addition, the egg capsules were collected from the same sites during the breeding season in August and stored at $-80^{\circ} \mathrm{C}$ until needed. The snails were defrosted under running water and the shell was removed by rupturing it carefully using a bench vice. The hypobranchial glands were excised according to Westley and 
Benkendorff [54] and then weighed on an analytical balance (Mettler-Toledo, Port Melbourne, Australia; precision $0.0001 \mathrm{~g}$ ).

The extraction of the secondary metabolites from the collected hypobranchial glands (16.06 g) or egg capsules ( 12 g) was undertaken according to established procedures [20]. Glands or egg masses were repeatedly soaked for $2 \mathrm{~h}$ in solvent (chloroform:methanol, 1:1), and replenished until a clear extract was obtained. The extract was then filtered through Whatman filter paper $1(90 \mathrm{~mm}$, Sigma-Aldrich) to remove the tissue. The filtered solvent was then decanted into a separating funnel, where the chloroform and the methanol partition were separated with addition of a small amount of MilliQ water. After the two phases formed, both solvent layers were collected separately then evaporated to dryness using a rotary evaporator (Buchi, Flawil, Switzerland). The chloroform partition was kept covered in aluminium foil to protect from photolytic degradation and dried using a vacuum pressure of $474 \mathrm{mbar}$ at $40^{\circ} \mathrm{C}$, then transferred to an amber vial and dried under high purity nitrogen gas before storage at $-80^{\circ} \mathrm{C}$. The methanol-water partition was dried using a rotational vacuum concentrator (Alpha-RVC, Martin Christ, Osterode, Germany) until it was totally dry. In a preliminary extraction, D. orbita stored for 12 months at $-20^{\circ} \mathrm{C}$ were dissected and the hypobranchical glands, which had already commenced oxidative and photolytic colour reactions, were used in the extraction. This extract is referred to as the "degraded HBG extract". To facilitate dissolving this extract in DMSO for anti-inflammatory testing, it was sonicated in a water bath for $30 \mathrm{~min}$, then heated at $60{ }^{\circ} \mathrm{C}$ for $10 \mathrm{~min}$, then further sonicated for $10 \mathrm{~min}$ and heated for $10 \mathrm{~min}$ two more times. For all other extracts and compounds examined, the sonication and heating steps were not required to facilitate solubility in DMSO prior to testing.

\subsection{Purification of Brominated Natural Products}

The crude chloroform extract from the hypobranchial glands was further fractionated using flash silica gel column chromatography in order to purify the main indole compounds. The separation of the compounds based on their colour and polarity by eluting from the silica column with increasingly polar solvents starting with hexane, then DCM, then increasing concentrations of methanol under nitrogen pressure, according to Esmaeelian et al. [22]. Six of the fractions were subject to preliminary bioassay and LC-MS screening and based on these results, further purification focused on the main brominated indoles tyrindoleninone, tyriverdin, and 6-bromoisatin.

For the separation of tyriverdin from the HBG chloroform extract, the extract was dissolved in hexane, which results in precipitation out of the solution. The precipitate was then centrifuged and the solvent was removed, before washing again in hexane, and repeating the procedure until a clean dried crystaline powder was obtained. To purify tyrindoleninone, the crude hypobranchial chloroform extract was separated using flash column chromatography pressurised with nitrogen gas. The stationary phase consisted of a slurry of silica gel 60 (63-200 $\mu \mathrm{m}$ particle size, 70-230 mesh) mixed with hexane for pouring. Crude extract $(426 \mathrm{mg})$ was loaded onto the column and eluted using a gradient of solvents. Fraction $1(\sim 120 \mathrm{~mL})$ was eluted with $100 \%$ hexane, fraction $2(\sim 70 \mathrm{~mL})$ was eluted with $20 \%$ DCM in hexane, fraction $3(\sim 230 \mathrm{~mL})$ was collected using $25 \%$ DCM in hexane, and fraction 4 with $100 \%$ DCM $(\sim 250 \mathrm{~mL})$. Fraction 2 containing tyrindoleninone was concentrated in a rotary evaporator at $40{ }^{\circ} \mathrm{C}$ and finally dried under $\mathrm{N}_{2}$ gas within amber vials for LC-MS analysis and activity testing.

\subsection{Chemical Analysis of the Extracts and Purified Compounds}

Extracts were analysed using an Agilent 1260 Infinity High Performance Liquid Chromatography (HPLC, Santa Clara, CA, USA) system coupled with a 6120 Quadrupole mass spectrometer (MS) according the method outlined in Valles-Regino et al. [41]. The HPLC was undertaken on a C18 reversed phase column $(100 \times 4.6 \mathrm{~mm}$; Phenomenex Luna, Torrance, CA, USA) using a solvent gradient from 10 to $95 \%$ acetonitrile (ACN), both with the addition of $0.005 \%$ trifluoroacetic acid (TFA) over $18 \mathrm{~min}$ at a flow rate of $0.75 \mathrm{~mL} / \mathrm{min}$. The eluent was also monitored using parallel UV/Vis 
diode-array detection (DAD). The mass spectrometer used electrospray ionisation (ESI) in both positive and negative ion modes, as well as selected ion monitoring for negatively charged brominated indole fragment ions at $m / z$ 224, 226. Agilent ChemStation was used to analyse the LC-MS data. Brominated indoles were identified by comparison of their retention times and characteristic mass spectra (with major doublet (singly brominated) or triplet (doubly brominated) mass ion clusters separated by 2 mass units for $\mathrm{Br}^{78}$ and $\mathrm{Br}^{81}$ ) as reported in previous studies [41,54].

The chloroform extracts and purified tyrindoleninone were also analysed using Gas chromatography-mass spectrometry (GC-MS) on a Hewlett Packard (HP) 6890 GC coupled to a HP 5973 mass selective detector (MSD; Palo Alto, CA, USA). The GC utilised a column of HP-5MS (Crosslinked 5\% PH ME Siloxane) with $30 \mathrm{~m} \times 0.25 \mathrm{~mm} \times 0.25 \mu \mathrm{m}$ film thickness. The column temperature was controlled by a HP ChemStation programmed from $50{ }^{\circ} \mathrm{C}$ ( $5 \mathrm{~min}$ hold) to $250{ }^{\circ} \mathrm{C}$ (5 min hold) at $10^{\circ} \mathrm{C} / \mathrm{min}$. The injection volume was $0.2 \mu \mathrm{L}$ using an Agilent 7683 series injector with the injection port (split 1:10) at $250^{\circ} \mathrm{C}$. Helium was used as the carrier gas with the flow rate of $0.7 \mathrm{~mL} / \mathrm{min}$, the MS detector source was set at $250{ }^{\circ} \mathrm{C}$ and quad at $150{ }^{\circ} \mathrm{C}$, with the transfer line at $280^{\circ} \mathrm{C}$ and ion source voltage of $69.9 \mathrm{eV}$. Data processing was done using HP ChemStation software and the identification of the volatile compounds was based on matches to the library mass spectra and fragmentations patterns (NIST02, WILEY 6, and ESSOILS in house; National Institute of Standards and Technology, Gaithersberg, MD, USA).

\subsection{Preparation of Extracts and Compounds}

All extract/compounds were dissolved in DMSO and tested at 5 different concentrations of 50, 10, $2,0.4$, and $0.08 \mu \mathrm{g} / \mathrm{mL}$ for all anti-inflammatory assays unless otherwise noted. The final concentration of DMSO was $0.35 \% v / v$ for extracts and compounds. All samples were tested in triplicate at each concentration and each assay was independently repeated at least 3 times. The concentrations used for the cytotoxicity assays were $50,25,12.5,6.25$. and $3.125 \mu \mathrm{g} / \mathrm{mL}$.

\subsection{Cytotoxicity Assay}

To check for cytotoxicity of the extracts and compounds against RAW264.7 mouse macrophage and $3 \mathrm{~T} 3 \mathrm{ccl}-92$ mouse fibroblast cell lines, the crystal violet cytotoxicity test was used according to the published protocol [55]. In brief, RAW264.7 cells were seeded with a density of $2 \times 10^{4}$ cells $/$ well in a 96-well plate and then incubated for 18-24 h. The following day the compounds/extracts were added and then incubated for $24 \mathrm{~h}$ before the media was aspirated and the cells washed twice in a gentle stream of water. After removing the water, $50 \mu \mathrm{L}$ of $0.5 \%$ crystal violet staining solution were added and the cells were incubated for $20 \mathrm{~min}$ at room temperature. The plate was then washed 4 times with water and air dried for $2 \mathrm{~h}$. Finally, $200 \mu \mathrm{L}$ of methanol was added to each well and incubated for $20 \mathrm{~min}$ at room temperature on a rocker. This was followed by measuring the optical density at $570 \mathrm{~nm}$ with a plate reader Anthos Zenyth 200rt (Anthos Labtec Instruments, Heerhugowaard, The Netherlands). Chlorambucil was used as a positive control.

\subsection{NO Inhibition Assay}

The NO inhibition assay was conducted according to published procedures [35,56-60]. RAW264.7 macrophages were seeded in a 96 well plate at a concentration of $6 \times 10^{5}$ cells $/ \mathrm{mL}$ in colour-free $10 \%$ FBS DMEM and incubated at $37^{\circ} \mathrm{C}$ in $5 \% \mathrm{CO}_{2}$ overnight. RAW264.7 macrophages were incubated $1 \mathrm{~h}$ with extracts/compounds prior to the addition of LPS. Dexamethasone at a concentration of $2.5 \mu \mathrm{M}$ was used as a positive control and $0.35 \%$ DMSO as a negative control. Then, $20 \mathrm{~h}$ after the addition of LPS, the supernatant was collected. The concentration of nitrite in the supernatant was measured using the Greiss reaction by adding an equal volume of the supernatant and Greiss reagent $(0.1 \%$ NED; $1 \%$ sulfanilic acid in $5 \%$ orthophosphoric acid) in a 96 well plate. The plates were incubated for 15-20 min in the dark, then read at $550 \mathrm{~nm}$ wavelength on an Anthos Zenyth 200rt (Anthos Labtec 
Instruments). Sodium nitrite was used to prepare a standard curve to quantify the nitrite from the absorbance readings in this assay.

\subsection{TNF-Alpha Inhibition Assay}

The amount of TNF $\alpha$ was quantified in cell culture media using murine TNF $\alpha$ ELISA kits (BD bioscience). In brief, the RAW264.7 mouse macrophages $\left(6 \times 10^{5}\right.$ cells $\left./ \mathrm{mL}\right)$ were stimulated with LPS $(100 \mathrm{ng} / \mathrm{mL}) 1 \mathrm{~h}$ after treatment with several concentrations of extracts $(0.08-50 \mu \mathrm{g} / \mathrm{mL})$. After $18 \mathrm{~h}$, the supernatant was collected and TNF $\alpha$ production was measured by reading the absorbance at $450 \mathrm{~nm}$ wavelength on an Anthos Zenyth 200rt microplate reader (Anthos Labtech Instruments). Dexamethasone at a concentration of $2.5 \mu \mathrm{M}$ was used as a positive control, with a negative control of $0.35 \%$ DMSO.

\subsection{PGE2 Inhibition Assay}

The levels of PGE2 were measured in cell media using a Cayman Prostaglandin $\mathrm{E}_{2}$ Express ELISA Kit (Cayman Chemical, Ann Arbor, MI, USA) according to the manufacturer's instructions. In brief, the 3 T3 ccl-92 fibroblasts $\left(1 \times 10^{5}\right.$ cells $\left./ \mathrm{mL}\right)$ were grown overnight in a 96-well plate and then treated with extracts/compounds $3 \mathrm{~h}$ before being stimulated with Calcium ionophore (50 $\mu \mathrm{M})$. After $20 \mathrm{~min}$, supernatants were collected and PGE2 production was quantified by measuring the absorbance at $405 \mathrm{~nm}$ wavelength with an Anthos Zenyth 200rt (Anthos Labtech Instruments). Indomethacin at a concentration of $100 \mu \mathrm{M}$ was used as a positive control and $\sim 0.5 \%$ DMSO as a negative control.

\subsection{Assessment of NFKB Translocation}

This assay was performed according to the published protocol in Olivera et al. [61]. RAW264.7 mouse macrophages were seeded at 400,000 cells/well in $800 \mu \mathrm{L}$ in 4-well chambered slides and incubated overnight. The cells were then incubated with the test samples $(40 \mu \mathrm{g} / \mathrm{mL} \mathrm{HBG}$ extract, 6-bromoisatin, or 6-bromoindole) for $1 \mathrm{~h}$ prior to stimulation with LPS $(700 \mathrm{ng} / \mathrm{mL})$ for $30 \mathrm{~min}$. After stimulation, the cells were washed with PBS and fixed with $3.7 \%$ paraformaldehyde for $15 \mathrm{~min}$. The fixed cells were then washed with PBS three times and permeabilised using $0.2 \%$ Triton-X 100 for $10 \mathrm{~min}$, followed by a PBS wash and finally blocked using the $0.1 \%$ bovine serum albumin (BSA) for $1 \mathrm{~h}$. The cells were washed with PBS and incubated with rabbit anti-p65 NFkB antibody (1:500) and goat anti-mouse IKB (1:500) overnight at $4{ }^{\circ} \mathrm{C}$. The following day, the cells were washed again three times with PBS and incubated for $1 \mathrm{~h}$ with goat-anti-rabbit IgG conjugated with Alexa Fluor 594 (1:1000) and donkey anti-mouse IgG conjugated with Alexa fluor 488 (1:1000) at room temperature. Finally, the cells were washed with PBS then mounted with Prolong mounting media containing DAPI before visualising using the Olympus Flouview FVi10 confocal microscope (Olympus, Tokyo, Japan). Using ImageJ (v1.50i, National Institutes of Health, Bethesda, MD, USA), an outline was drawn around each nucleus by adjusting the colour threshold of DAPI. Mean fluorescence inside the nucleus was measured, along with several adjacent background readings. The total corrected cellular fluorescence (TCCF) was calculated by applying the equation TCCF $=$ integrated density $-($ area of selected cell $\times$ mean fluorescence of background readings) [62]. This TCCF was then used to calculate the \%inhibition of the NFKB translocation against the positive control where the cells were treated with LPS in the presence of the Vehicle (0.35\% DMSO $v / v)$ in Microsoft Office Excel 2013 (Redmond, WA, USA).

\subsection{Statistical Analysis}

All data were processed in Microsoft Office Excel 2013 (MS) first to obtain descriptive statistics. One-way Analysis of Variance (ANOVA) followed by Dunnett's multiple comparisons test was performed using GraphPad Prism version 6.00 for Windows (GraphPad Software, La Jolla, CA, USA, www.graphpad.com), with $p<0.05$ considered significant. The inhibitory concentration responsible for a $50 \%$ reduction in cell viability or production of inflammatory markers $\left(\mathrm{IC}_{50}\right)$ was calculated using the regression analysis, Probit in SPSS v21. 
Supplementary Materials: The following are available online at www.mdpi.com/1660-3397/15/5/133/s1.

Acknowledgments: This research was facilitated by an anonymous philanthropic research grant to K.B., a Libyan Embassy postgraduate research scholarship to T.B.A. and postgraduate research funding by the School of Environment, Science and Engineering, Southern Cross University. The authors are grateful to Ashley Dowell for access to facilities in the Analytical Research Laboratory, Southern Cross University and the Centre for Health Sciences Research, University of Southern Queensland.

Author Contributions: T.B.A. and and K.B. conceived and designed the experiments, with some input from all authors; T.B.A. performed the anti-inflammatory and cytotoxicity experiments and analysed the data, with support from J.S. and L.M.S.; D.R. assisted in the extraction, purified the natural products, and ran the LC-MS/GC-MS analysis and assisted in the interpretation of chemical data, with additional support from P.M. and K.B. T.B.A. wrote the first draft with significant contributions from K.B. and D.R.; All authors read and approved the final manuscript.

Conflicts of Interest: The authors declare no conflict of interest.

\section{References}

1. Alessandri, A.L.; Sousa, L.P.; Lucas, C.D.; Rossi, A.G.; Pinho, V.; Teixeira, M.M. Resolution of inflammation: Mechanisms and opportunity for drug development. Pharmacol. Ther. 2013, 139, 189-212. [CrossRef] [PubMed]

2. Fujiwara, N.; Kobayashi, K. Macrophages in inflammation. Curr. Drug Targets Inflamm. Allergy 2005, 4, 281-286. [CrossRef] [PubMed]

3. Karin, M.; Greten, F.R. Nf-kappab: Linking inflammation and immunity to cancer development and progression. Nat. Rev. Immunol. 2005, 5, 749-759. [CrossRef] [PubMed]

4. Lo, C.J.; Chiu, K.C.; Fu, M.; Lo, R.; Helton, S. Fish oil decreases macrophage tumor necrosis factor gene transcription by altering the NF kappa B activity. J. Surg. Res. 1999, 82, 216-221. [CrossRef] [PubMed]

5. Moraes, V.L.G.; Vargaftig, B.B.; Lefort, J.; Meager, A.; Chignard, M. Effect of cyclo-oxygenase inhibitors and modulators of cyclic AMP formation on lipopolysaccharide-induced neutrophil infiltration in mouse lung. Br. J. Pharmacol. 1996, 117, 1792-1796. [CrossRef]

6. Wink, D.A.; Grisham, M.B.; Mitchell, J.B.; Ford, P.C. Direct and indirect effects of nitric oxide in chemical reactions relevant to biology. Methods Enzymol. 1996, 268, 12-31. [PubMed]

7. Tamir, S.; Burney, S.; Tannenbaum, S.R. DNA damage by nitric oxide. Chem. Res. Toxicol. 1996, 9, 821-827. [CrossRef] [PubMed]

8. Yuan, G.; Wahlqvist, M.L.; He, G.; Yang, M.; Li, D. Natural products and anti-inflammatory activity. Asia Pac. J. Clin. Nutr. 2006, 15, 143-152. [PubMed]

9. Mayer, A.M.S. Marine Pharmaceuticals: The Clinical Pipeline. Available online: http://marinepharmacology. midwestern.edu/clinPipeline.htm (accessed on 9 October 2016).

10. Ciavatta, M.L.; Lefranc, F.; Carbone, M.; Mollo, E.; Gavagnin, M.; Betancourt, T.; Dasari, R.; Kornienko, A.; Kiss, R. Marine mollusk-derived agents with antiproliferative activity as promising anticancer agents to overcome chemotherapy resistance. Med. Res. Rev. 2016. [CrossRef] [PubMed]

11. Benkendorff, K. Molluscan biological and chemical diversity: Secondary metabolites and medicinal resources produced by marine molluscs. Biol. Rev. Camb. Philos. Soc. 2010, 85, 757-775. [CrossRef] [PubMed]

12. Brien, S.; Prescott, P.; Coghlan, B.; Bashir, N.; Lewith, G. Systematic review of the nutritional supplement Perna canaliculus (green-lipped mussel) in the treatment of osteoarthritis. QJM 2008, 101, 167-179. [CrossRef] [PubMed]

13. Chellaram, C.; Edward, J.K.P. Anti-inflammatory potential of coral reef associated gastropod. Drupa Margarit. Indian J. Sci. Technol. 2009, 2, 75-77.

14. Santhi, V.; Sivakumar, V.; Thangathirupathi, A.; Thilaga, R.D. Analgesic, anti-pyretic and anti-inflammatory activities of chloroform extract of prosobranch mollusc Purpura persica. Int. J. Pharm. Biol. Sci. 2011, 5, 9-15.

15. Badiu, D.L.; Balu, A.M.; Barbes, L.; Luque, R.; Nita, R.; Radu, M.; Tanase, E.; Rosoiu, N. Physico-chemical characterisation of lipids from Mytilus galloprovincialis (L.) and Rapana venosa and their healing properties on skin burns. Lipids 2008, 43, 829-841. [CrossRef] [PubMed]

16. Benkendorff, K.; Rudd, D.; Nongmaithem, B.D.; Liu, L.; Young, F.; Edwards, V.; Avila, C.; Abbott, C.A. Are the traditional medical uses of Muricidae molluscs substantiated by their pharmacological properties and bioactive vompounds? Mar. Drugs 2015, 13, 5237-5275. [CrossRef] [PubMed] 
17. Benkendorff, K. Natural product research in the Australian marine invertebrate Dicathais orbita. Mar. Drugs 2013, 11, 1370-1398. [CrossRef] [PubMed]

18. Vine, K.L.; Locke, J.M.; Ranson, M.; Benkendorff, K.; Pyne, S.G.; Bremner, J.B. In vitro cytotoxicity evaluation of some substituted isatin derivatives. Bioorg. Med. Chem. 2007, 15, 931-938. [CrossRef] [PubMed]

19. Benkendorff, K.; McIver, C.M.; Abbott, C.A. Bioactivity of the murex homeopathic remedy and of extracts from an Australian muricid mollusc against human cancer cells. Evid. Based Complement. Altern. Med. 2011, 2011, 879585. [CrossRef] [PubMed]

20. Edwards, V.; Benkendorff, K.; Young, F. Marine compounds selectively induce apoptosis in female reproductive cancer cells but not in primary-derived human reproductive granulosa cells. Mar. Drugs 2012, 10, 64-83. [CrossRef] [PubMed]

21. Esmaeelian, B.; Abbott, C.A.; Le Leu, R.K.; Benkendorff, K. 6-bromoisatin found in muricid mollusc extracts inhibits colon cancer cell proliferation and induces apoptosis, preventing early stage tumor formation in a colorectal cancer rodent model. Mar. Drugs 2014, 12, 17-35. [CrossRef] [PubMed]

22. Esmaeelian, B.; Benkendorff, K.; Johnston, M.R.; Abbott, C.A. Purified brominated indole derivatives from Dicathais orbita induce apoptosis and cell cycle arrest in colorectal cancer cell lines. Mar. Drugs 2013, 11, 3802-3822. [CrossRef] [PubMed]

23. Westley, C.B.; McIver, C.M.; Abbott, C.A.; Le Leu, R.K.; Benkendorff, K. Enhanced acute apoptotic response to azoxymethane-induced DNA damage in the rodent colonic epithelium by tyrian purple precursors: A potential colorectal cancer chemopreventative. Cancer Biol. Ther. 2010, 9, 371-379. [CrossRef] [PubMed]

24. Esmaeelian, B.; Benkendorff, K.; Le Leu, R.; Abbot, C. Simultaneous assessment of the efficacy and toxicity of marine mollusc derived brominated indoles in an in vivo model for early stage colon cancer. Integr. Cancer Ther. 2017. [CrossRef] [PubMed]

25. Benkendorff, K.; Bremner, J.B.; Davis, A.R. Tyrian purple precursors in the egg masses of the Australian muricid, Dicathais orbita: A possible defensive role. J. Chem. Ecol. 2000, 26, 1037-1050. [CrossRef]

26. Meijer, L.; Skaltsounis, A.L.; Magiatis, P.; Polychronopoulos, P.; Knockaert, M.; Leost, M.; Ryan, X.P.; Vonica, C.A.; Brivanlou, A.; Dajani, R.; et al. Gsk-3-selective inhibitors derived from Tyrian purple indirubins. Chem. Biol. 2003, 10, 1255-1266. [CrossRef] [PubMed]

27. Nam, S.; Buettner, R.; Turkson, J.; Kim, D.; Cheng, J.Q.; Muehlbeyer, S.; Hippe, F.; Vatter, S.; Merz, K.H.; Eisenbrand, G.; et al. Indirubin derivatives inhibit stat 3 signaling and induce apoptosis in human cancer cells. Proc. Natl. Acad. Sci. USA 2005, 102, 5998-6003. [CrossRef] [PubMed]

28. Kim, S.A.; Kim, Y.C.; Kim, S.W.; Lee, S.H.; Min, J.J.; Ahn, S.G.; Yoon, J.H. Antitumor activity of novel indirubin derivatives in rat tumor model. Clin. Cancer Res. 2007, 13, 253-259. [CrossRef] [PubMed]

29. Leclerc, S.; Garnier, M.; Hoessel, R.; Marko, D.; Bibb, J.A.; Snyder, G.L.; Greengard, P.; Biernat, J.; $\mathrm{Wu}$, Y.-Z.; Mandelkow, E.-M. Indirubins inhibit glycogen synthase kinase- $3 \beta$ and $\mathrm{cdk} 5 / \mathrm{p} 25$, two protein kinases involved in abnormal tau phosphorylation in alzheimer's disease: A property common to most cyclin-dependent kinase inhibitors? J. Biol. Chem. 2001, 276, 251-260. [CrossRef] [PubMed]

30. Karabelas, K.; Lepistö, M.; Sjö, P. Protein Kinase Inhibitors. U.S. Patent 6,346,625 B1, 12 February 2002.

31. Wang, L.; Liu, X.; Chen, R. Derivatives of Isoindigo, Indigo and Indirubin and Methods of Treating Cancer. U.S. Patent 6,933,315 B2, 13 August 2005.

32. Carson, D.A.; Leoni, L.M.; Cottam, H.B. Indole Compounds Useful for the Treatment of Cancer. U.S. Patent 7,151,100 B1, 19 December 2006.

33. Corson, T.W.; Crews, C.M. Molecular understanding and modern application of traditional medicines: Triumphs and trials. Cell 2007, 130, 769-774. [CrossRef] [PubMed]

34. Thun, M.J.; Henley, S.J.; Patrono, C. Nonsteroidal anti-inflammatory drugs as anticancer agents: Mechanistic, pharmacologic and clinical issues. J. Natl. Cancer Inst. 2002, 94, 252-266. [CrossRef] [PubMed]

35. Wei, W.C.; Sung, P.J.; Duh, C.Y.; Chen, B.W.; Sheu, J.H.; Yang, N.S. Anti-inflammatory activities of natural products isolated from soft corals of taiwan between 2008 and 2012. Mar. Drugs 2013, 11, 4083-4126. [CrossRef] [PubMed]

36. Kim, J.K.; Park, G.M. Indirubin-3-monoxime exhibits anti-inflammatory properties by down-regulating nf-kappab and jnk signaling pathways in lipopolysaccharide-treated RAW264.7 cells. Inflamm. Res. 2012, 61, 319-325. [CrossRef] [PubMed] 
37. Matheus, M.E.; Violante, F.A.; Garden, S.J.; Pinto, A.C.; Fernandes, P.D. Isatins inhibit cyclooxygenase-2 and inducible nitric oxide synthase in a mouse macrophage cell line. Eur. J. Pharmacol. 2007, 556, 200-206. [CrossRef] [PubMed]

38. Kitaura, Y.; Ito, F.; Stevens, R.W.; Asai, N. Antiallergy and Antiinflammatory Agents. U.S. Patent 5,006,541 A, 9 April 1991.

39. Stevens, R.W.; Morita, H.; Nakane, M. Indole Derivatives as Antiallergy and Antiinflammatory Agents. U.S. Patent 5,290,788 A, 1 March 1994.

40. Pelcman, B.; Olofsson, K.; Katkevics, M.; Ozola, V.; Suna, E.; Kalvins, I.; Trapencieris, P.; Katkevica, D.; Schaal, W. Indoles Useful in the Treatment of Inflammation. U.S. Patent 20100197687 A1, 5 August 2010.

41. Valles-Regino, R.; Mouatt, P.; Rudd, D.; Yee, L.H.; Benkendorff, K. Extraction and quantification of bioactive Tyrian purple precursors: A comparative and validation study from the hypobranchial gland of a muricid Dicathais orbita. Molecules 2016, 21, 1672. [CrossRef] [PubMed]

42. Cooksey, C.J. Tyrian purple: 6,6'-dibromoindigo and related compounds. Molecules 2001, 6, 736-769. [CrossRef]

43. Baker, J.; Duke, C. Chemistry of the indoleninones. II. Isolation from the hypobranchial glands of marine molluscs of 6-bromo-2, 2-dimethylthioindolin-3-one and 6-bromo-2-methylthioindoleninone as alternative precursors to Tyrian purple. Aust. J. Chem. 1973, 26, 2153-2157. [CrossRef]

44. Lee, D.; Long, S.A.; Murray, J.H.; Adams, J.L.; Nuttall, M.E.; Nadeau, D.P.; Kikly, K.; Winkler, J.D.; Sung, C.M.; Ryan, M.D.; et al. Potent and selective nonpeptide inhibitors of caspases 3 and 7. J. Med. Chem. 2001, 44, 2015-2026. [CrossRef] [PubMed]

45. Hoessel, R.; Leclerc, S.; Endicott, J.A.; Nobel, M.E.; Lawrie, A.; Tunnah, P.; Leost, M.; Damiens, E.; Marie, D.; Marko, D.; et al. Indirubin, the active constituent of a chinese antileukaemia medicine, inhibits cyclin-dependent kinases. Nat. Cell Biol. 1999, 1, 60-67. [PubMed]

46. Yuskaitis, C.J.; Jope, R.S. Glycogen synthase kinase-3 regulates microglial migration, inflammation, and inflammation-induced neurotoxicity. Cell Signal 2009, 21, 264-273. [CrossRef] [PubMed]

47. Kunikata, T.; Tatefuji, T.; Aga, H.; Iwaki, K.; Ikeda, M.; Kurimoto, M. Indirubin inhibits inflammatory reactions in delayed-type hypersensitivity. Eur. J. Pharmacol. 2000, 410, 93-100. [CrossRef]

48. Hamburger, M.; Jahne, E.; Butterweck, V.; Oufir, M.; Eigenmann, D.; Culot, M.; Cecchelli, R.; Walter, F.; Deli, M.; Smiesko, M. Pharmacokinetic, in vitro and in silico assessment of anti-inflammatory alkaloids from Isatis tinctoria L. Planta Med. 2015, 81, 901. [CrossRef]

49. Lai, J.L.; Liu, Y.H.; Liu, C.; Qi, M.P.; Liu, R.N.; Zhu, X.F.; Zhou, Q.G.; Chen, Y.Y.; Guo, A.Z.; Hu, C.M. Indirubin inhibits LPS-induced inflammation via TLR4 abrogation mediated by the NF-kB and MAPK signaling pathways. Inflammation 2017, 40,1-12. [CrossRef] [PubMed]

50. Lopes, F.C.; Calvo, T.R.; Colombo, L.L.; Vilegas, W.; Carlos, I.Z. Immunostimulatory and cytotoxic activities of Indigofera suffruticosa (Fabaceae). Nat. Prod. Res. 2011, 25, 1796-1806. [CrossRef] [PubMed]

51. Murakami, A.; Ohigashi, H. Targeting NOX, INOS and COX-2 in inflammatory cells: Chemoprevention using food phytochemicals. Int. J. Cancer 2007, 121, 2357-2363. [CrossRef] [PubMed]

52. Krakauer, T. Molecular therapeutic targets in inflammation: Cyclooxygenase and NF-кB. Curr. Drug Targets Inflamm. Allergy 2004, 3, 317-324. [CrossRef] [PubMed]

53. Meijer, L.; Shearer, J.; Bettayeb, K.; Ferandin, Y. Diversity of intracellular mechanisms underlying the anti-tumor properties of indirubins. In Indirubin, the Red Shade of Indigo; Meijer, L., Guyard, N., Skaltsounis, A.-L., Eisenbrand, G., Eds.; Life in Progress Editions: Roscoff, France, 2006; pp. 235-246.

54. Westley, C.; Benkendorff, K. Sex-specific Tyrian purple genesis: Precursor and pigment distribution in the reproductive system of the marine mollusc, Dicathais orbita. J. Chem. Ecol. 2008, 34, 44-56. [CrossRef] [PubMed]

55. Feoktistova, M.; Geserick, P.; Leverkus, M. Crystal violet assay for determining viability of cultured cells. Cold Spring Harb. Protoc. 2016, 2016. [CrossRef] [PubMed]

56. Gunawardena, D.; Shanmugam, K.; Low, M.; Bennett, L.; Govindaraghavan, S.; Head, R.; Ooi, L.; Munch, G. Determination of anti-inflammatory activities of standardised preparations of plant- and mushroom-based foods. Eur. J. Nutr. 2014, 53, 335-343. [CrossRef] [PubMed]

57. Whitehouse, M.W.; Macrides, T.A.; Kalafatis, N.; Betts, W.H.; Haynes, D.R.; Broadbent, J. Anti-inflammatory activity of a lipid fraction (lyprinol) from the NZ green-lipped mussel. Inflammopharmacology 1997, 5, 237-246. [CrossRef] [PubMed] 
58. Yun, K.J.; Kim, J.Y.; Kim, J.B.; Lee, K.W.; Jeong, S.Y.; Park, H.J.; Jung, H.J.; Cho, Y.W.; Yun, K.; Lee, K.T. Inhibition of LPS-induced NO and PGE2 production by asiatic acid via NK-kappa B inactivation in RAW 264.7 macrophages: Possible involvement of the ikK and MAPK pathways. Int. Immunopharmacol. 2008, 8 , 431-441. [CrossRef] [PubMed]

59. Phanse, M.A. In Vivo and in vitro screening of medicinal plants for their anti-inflammatory activity: An overview. J. Appl. Pharm. Sci. 2012, 2, 19-33. [CrossRef]

60. Kim, D.S.; Shin, M.R.; Kim, Y.S.; Bae, W.J.; Roh, D.H.; Hwang, Y.S.; Kim, E.C. Anti-inflammatory effects of glutamine on LPS-stimulated human dental pulp cells correlate with activation of MKP-1 and attenuation of the MAPK and NF-kappa b pathways. Int. Endod. J. 2015, 48, 220-228. [CrossRef] [PubMed]

61. Olivera, A.; Moore, T.W.; Hu, F.; Brown, A.P.; Sun, A.; Liotta, D.C.; Snyder, J.P.; Yoon, Y.; Shim, H.; Marcus, A.I. Inhibition of the NF-kb signaling pathway by the curcumin analog, 3, 5-bis (2-pyridinylmethylidene)-4-piperidone (ef31): Anti-inflammatory and anti-cancer properties. Int. Immunopharmacol. 2012, 12, 368-377. [CrossRef] [PubMed]

62. McCloy, R.A.; Rogers, S.; Caldon, C.E.; Lorca, T.; Castro, A.; Burgess, A. Partial inhibition of CDK1 in G2 phase overrides the SAC and decouples mitotic events. Cell Cycle 2014, 13, 1400-1412. [CrossRef] [PubMed]

(C) 2017 by the authors. Licensee MDPI, Basel, Switzerland. This article is an open access article distributed under the terms and conditions of the Creative Commons Attribution (CC BY) license (http:/ / creativecommons.org/licenses/by/4.0/). 